\title{
Formulation and evaluation of curcumin microsponges for oral and topical drug delivery
}

\author{
Meenakshi Bhatia ${ }^{1} \cdot$ Megha Saini $^{1}$
}

Received: 19 April 2018 / Accepted: 7 September 2018 / Published online: 21 September 2018

(c) The Author(s) 2018

\begin{abstract}
The aim of the present study was to improve the release rate of curcumin by microsponges prepared through quasi-emulsion solvent diffusion technique using ethylcellulose and PVA as carriers. The microsponges were characterized by FTIR, DSC, XRD and SEM studies followed by determination of total drug content and entrapment efficiency. The prepared microsponges were further filled in hard gelatin capsule shell and then loaded in carbopol gel to evaluate its potential in oral and topical drug delivery. Further, it was observed from the studies on release rate that microsponges filled in hard gelatin capsule shells (batch MS4) showed 93.2\% release of curcumin whereas pure curcumin filled in capsule showed only $11.7 \%$ release in $8 \mathrm{~h}$ study. Furthermore, the microsponges loaded in carbopol gel were evaluated for ex vivo drug deposition studies and it was found that $77.5 \%$ of the curcumin was released within $24 \mathrm{~h}$. The estimated drug remained in the skin was $207.61 \pm 5.03 \mu \mathrm{g} /$ $\mathrm{cm}^{2}$ as determined by a Franz diffusion cell. The drug release profile data were found to be fitted best into the zero-order model with anomalous transport mechanism of drug release in both cases.
\end{abstract}

Keywords Curcumin $\cdot$ Microsponges $\cdot$ Quasi-emulsion solvent diffusion technique

\section{Introduction}

Microsponges are extremely cross-linked, non-collapsible, porous, polymeric microspheres having particle size range from 5 to $300 \mu \mathrm{m}$ that can entrap wide range of active ingredients and release them over extended time (Osmani et al. 2015). Microsponges have unique dissolution and compression properties due to their sponge-like texture (Jangde 2011). They are highly effective, stable, non-irritant, nontoxic, non-allergic, non-mutagenic and also minimum side effects with improved patient compliance (Amrutiya et al. 2009). Various polymers like Eudragit RS100, ethylcellulose, polystyrene, PHEMA, etc. have been utilized in forming microsponges. Further, these active microsponges can be incorporated into formulations, such as capsules, gel and powders, and share a broad package of benefits (Pawar et al. 2015; Bothiraja et al. 2014; Li et al. 2013; Deshmukh and Poddar 2012; Jain and Singh 2011; Jain et al. 2011). The

Meenakshi Bhatia

meenaxibhatia@gmail.com

1 Drug Delivery Research Laboratory, Department of Pharmaceutical Sciences, Guru Jambheshwar University of Science and Technology, Hisar 125001, India microsponges have demonstrated their use in cosmetics and pharmaceuticals viz. antifungal vaginal gel, in augmented arthritis therapy, as silver sulfadiazine-loaded microsponge gel for burn wounds, in gastroretentive delivery, as matrix tablet and in colon-specific drug delivery system, etc. (Salwa et al. 2018; Riyaz Ali et al. 2015; Kumar and Ghosh 2017; Arya and Pathak 2014; Mine et al. 2006).

Curcumin (CUR) is a yellow colored naturally occurring polyphenol compound obtained from the rhizomes of Curcuma longa, family Zingiberaceae. It is a highly pleiotropic molecule which can interact with different molecular targets involved in inflammation (Ornchuma et al. 2014). It can change inflammatory response by downregulating the activity of cyclooxegenase 2 (COX2), lipoxygenase, and inducible iNOS (nitric oxide synthase) enzyme. Curcumin being a natural substance is non-toxic even at higher dose (Aziz et al. 2007).

The present study was designed with the objective to enhance the dissolution and thus the release rate of the drug and bioadhesive potential of the preparation. Curcumin-loaded microsponges were prepared by quasi-emulsion solvent diffusion method using ethyl cellulose (EC) and polyvinyl alcohol (PVA). The microsponges were characterized by FTIR, DSC, SEM and XRD studies. The prepared microsponges were filled 
in hard gelatin capsule shells and also loaded in carbopol gel. The capsules were evaluated by different pharmacopoeial tests and also the mechanical strength of the gel was determined by texture analyzer. The total drug content, production yield, mean particle size and entrapment efficiency were calculated. The formed microsponges were demonstrated for their applications in oral and topical delivery systems. The preparation was further evaluated for its in vitro drug release behavior and ex vivo bioadhesion studies using a Franz diffusion cell.

\section{Experimental}

\section{Materials}

Curcumin was obtained as a gift sample from Konark Herbal and Health Care, Mumbai, India. The reagents including ethyl cellulose were obtained from High Purity Laboratory Chemicals, Mumbai. Polyvinyl alcohol, dichloromethane, methanol, lactose monohydrate, magnesium stearate, triethanolamine, polyvinyl alcohol, propylene glycol, carbopol 934P and $N$-methyl-2-pyrrolidone were procured from SD Fine-Chem. Limited, Mumbai. Potassium dihydrogen orthophosphate anhydrous (monobasic), starch and acacia were obtained from Central Drug House (CDH, India). Disodium hydrogen phosphate dihydrate $\left(\mathrm{Na}_{2} \mathrm{HPO}_{4} \cdot 2 \mathrm{H}_{2} \mathrm{O}\right)$ and sodium lauryl sulfate were provided by Hi-Media lab. Pvt. Ltd. All other chemicals were of reagent grades and used as procured.

\section{Methods}

\section{Preparation of curcumin microsponges}

Curcumin (CUR) microsponges were prepared by quasiemulsion solvent diffusion method (Jain and Singh 2010). The internal phase consisted of ethyl cellulose $(2 \% \mathrm{w} / \mathrm{v})$ in dichloromethane. The drug $(100-500 \mathrm{mg})$ was gradually added to the EC solution with continuous stirring at $600 \mathrm{rpm}$. The internal phase was then added dropwise into the aqueous external phase containing polyvinyl alcohol $(0.5 \% \mathrm{w} / \mathrm{v})$ (Table 1$)$. After $2 \mathrm{~h}$ of stirring, the microsponges were formed by evaporation of dichloromethane from the system. The microsponges were filtered and then dried in hot air oven at $40{ }^{\circ} \mathrm{C}$ till constant weight and stored in air tight container.

\section{Characterization of microsponges}

\section{Particle size analysis}

The mean particle size and polydispersity index (PdI) of all the batches of microsponges were measured using Mastersizer 2000 (Malvern Instruments Ltd.) at $25^{\circ} \mathrm{C}$.
Table 1 Composition of different batches of microsponge formulations

\begin{tabular}{lllll}
\hline Formulation & Curcumin (mg) & $\begin{array}{l}\text { Ethyl } \\
\text { cellulose } \\
(\mathrm{mg})\end{array}$ & $\begin{array}{l}\text { Dichlo- } \\
\text { romethane } \\
(\mathrm{mL})\end{array}$ & $\begin{array}{l}\text { Polyvinyl } \\
\text { alcohol }(\mathrm{g})\end{array}$ \\
\hline MS1 & 100 & 100 & 5 & 0.5 \\
MS2 & 200 & 100 & 5 & 0.5 \\
MS3 & 300 & 100 & 5 & 0.5 \\
MS4 & 400 & 100 & 5 & 0.5 \\
MS5 & 500 & 100 & 5 & 0.5 \\
\hline
\end{tabular}

\section{Total drug content and entrapment efficiency}

The weighed amounts of drug-loaded microsponges (10 mg) were dissolved in $10 \mathrm{~mL}$ methanolic phosphate buffer solution ( $\mathrm{pH}$ 7.4) with occasional stirring. $1 \mathrm{~mL}$ of the above sample was appropriately diluted with methanolic phosphate buffer and the absorbance was taken at $428 \mathrm{~nm}$ against blank using methanolic phosphate buffer solution where the value of $E_{1 \%}$ is 0.206 . The total drug content was calculated as follows (Eq. 1):

Total drug content $=\frac{\mathrm{Abs}}{E_{1 \%}} \times$ dilution factor $\times 10$.

The drug entrapment efficiency (\%) was calculated as (Eq. 2):

$\% \mathrm{EE}=\mathrm{TDC} /$ amount of drug added $\times 100$,

where TDC is the total drug content in microsponges and $\% \mathrm{EE}$ is the percentage of entrapment efficiency of the microsponges (Arya and Pathak 2014).

\section{Fourier transform infrared spectroscopy (FTIR)}

CUR, EC and CUR microsponges samples were subjected to Fourier transform infrared spectroscopy using $\mathrm{KBr}$ pellets in a Fourier transform infrared spectrophotometer (Perkin Elmer spectrum BX II) in the range from 4000 to $400 \mathrm{~cm}^{-1}$.

\section{Differential scanning calorimetry (DSC) analysis}

DSC analysis of CUR and CUR microsponges was carried out by heating the samples from 30 to $300{ }^{\circ} \mathrm{C}$ at a heating rate of $10{ }^{\circ} \mathrm{C}$ per min using DSC (SDT, Q600, TA instruments, USA).

\section{Scanning electron microscopy (SEM)}

The shape and surface of the CUR microsponges were examined using SEM (SEM, Environmental Scanning Electron Microscope model FEI Quanta 200F with Oxford-EDS system IE $250 \times$ Max 80, The Netherlands) after coating. Prior 
to observation, the samples were mounted on metal grids, using double-sided adhesive tape and coated with gold under vacuum.

\section{X-ray diffraction (XRD) study}

The CUR, EC and CUR microsponges powder samples were scanned using an X-ray diffractometer (Miniflex 2, Rigaku, Japan) from $0^{\circ}$ to $50^{\circ}$ diffraction angle $(2 \theta)$ range under the following measurement conditions: source, nickel filtered $\mathrm{CuK} \alpha$ radiation; voltage $35 \mathrm{kV}$; current $25 \mathrm{~mA}$; scan speed $0.05 \mathrm{~min}^{-1}$, division slit $1.25^{\circ}$, receiving slit $0.3 \mathrm{~mm}$.

\section{Stability study}

The stability studies of CUR microsponges were carried out in accelerated conditions as per ICH guidelines. The microsponge formulations were kept at $40{ }^{\circ} \mathrm{C} \pm 2{ }^{\circ} \mathrm{C}$ and $75 \% \pm 5 \%$ RH for 3 months. After 3 months, microsponges were analyzed for physical appearance, in vitro drug release and FTIR spectroscopy.

\section{Evaluation of capsules containing CUR microsponges}

After filling the CUR microsponges in capsule shells along with the excipients starch, acacia, sodium lauryl sulfate, lactose monohydrate and magnesium stearate, the filled capsules were evaluated for their organoleptic properties (size, shape and color, etc.). The weight variation and the disintegration tests were performed on filled capsules as per the methods specified in IP 2007. All the experiments were performed in triplicate.

\section{In vitro drug release study}

In vitro release rate study of CUR microsponges filled in capsule shell was carried out using a USP type I dissolution apparatus (TDL-08L Electrolab, India). Each jar was provided with one capsule in $900 \mathrm{~mL}$ of dissolution media, i.e., methanolic phosphate buffer ( $\mathrm{pH}$ 7.4) and maintained at temperature of $37.0 \pm 0.5{ }^{\circ} \mathrm{C}$ with continuous stirring at $50 \mathrm{rpm}$ for $8 \mathrm{~h}$. An aliquot of $5 \mathrm{~mL}$ sample was withdrawn at different time intervals and the same volume was replaced with fresh methanolic phosphate buffer. The content of CUR released was spectrophotometrically analyzed by measuring the absorbance at $\lambda_{\max }$ of $428 \mathrm{~nm}$. The mechanism of drug release from the capsules was determined by fitting the release data into several release kinetic models like zeroorder, first-order, and Higuchi and Korsmeyer/Peppas plots (Higuchi 1961, Mathew et al. 2009).

\section{Preparation of gel containing curcumin microsponges}

Carbopol 934P (1\% w/v) was initially soaked in water for $2 \mathrm{~h}$ and homogenously dispersed by agitation at $600 \mathrm{rpm}$ using magnetic stirrer. Curcumin microsponges were then uniformly dispersed in carbopol gel. Triethanolamine (2\% $\mathrm{v} / \mathrm{v}$ ) was added to neutralize the $\mathrm{pH}$. To this aqueous dispersion, propylene glycol and $N$-methyl-2-pyrrolidone were added as permeation enhancers.

\section{Evaluation of gel containing CUR microsponges}

After visual examination of the gel for its consistency, color and homogeneity, the gel was further evaluated for following parameters.

\section{pH determination}

The $\mathrm{pH}$ of the prepared gel was measured using $\mathrm{pH}$ meter (standardized using buffer, $\mathrm{pH} 7$ before use) by putting the tip of the electrode into the gel and after 2 min the result was recorded. The measurement of $\mathrm{pH}$ of formulation was done in triplicate and the mean value was calculated.

\section{Spreadability}

Spreadibility of the gel was determined after placing a weighed amount of sample between 2 glass slides and a weight of $500 \mathrm{~g}$ was kept over the slides for about $5 \mathrm{~min}$ after which no more spreading was expected. Diameters of spread circles (initial and final) were measured in $\mathrm{cm}$ and were taken as comparative values for spreadability.

\section{Viscosity}

Rheology includes the measurement of viscosity in centipoise, which indicates resistance of a fluid to flow. The viscosity of gel was measured by Brookfield viscometer using spindle No. 7 at different rpm at room temperature.

\section{Mechanical characterization of gels}

Structural analysis of carbopol gel and curcumin microsponges gel was done to determine their mechanical properties such as hardness, cohesiveness, and adhesiveness. Mechanical characterization was conducted employing a software-controlled penetrometer (TA-XT2, Stable Micro Systems, UK) by measuring the resistance to penetration and withdrawal of the needle probe (diameter $2 \mathrm{~mm}$ ) with pre-test speed of $1.5 \mathrm{~mm} / \mathrm{s}$, test speed $1.0 \mathrm{~mm} / \mathrm{s}$ and post-test speed of $10 \mathrm{~mm} / \mathrm{s}$. The needle probe $(2 \mathrm{~mm})$ was compressed down into the samples at a constant rate of $1.0 \mathrm{~mm} / \mathrm{s}$ to a 
depth of $8 \mathrm{~mm}$. The study was carried out in triplicate and the results were expressed as mean \pm SD. From the resulting texturogram, hardness and adhesiveness were calculated (Bhatia and Ahuja 2013).

\section{Ex vivo drug deposition studies}

Drug deposition study was performed on the excised rat abdominal skin using a Franz diffusion cell (Padamwar and Pokharkar 2006). Epidermal side of the skin was exposed to ambient condition, while dermal side was kept facing the receptor solution. Receptor compartment containing $30 \mathrm{~mL}$ phosphate buffer $\mathrm{pH} 7.4$ was thermostated at $37 \pm 0.5^{\circ} \mathrm{C}$ and stirred at $600 \mathrm{rpm}$. The skin was saturated with diffusion medium for $1 \mathrm{~h}$ before the application of sample. A $100 \mathrm{mg}$ of gel sample (equivalent to $30 \mathrm{mg}$ curcumin) was applied on the donor compartment. The samples were withdrawn at different time intervals. For determination of drug deposited in the skin, the diffusion cell was dismantled at the end of the run $(24 \mathrm{~h})$. The skin was carefully removed and drug present on the skin surface was cleaned with distilled water and analyzed for drug content.

\section{Quantification of curcumin from the skin samples}

Drug was extracted from the skin using a modified procedure (Echevarria et al. 2003). Briefly, the skin was cut into small pieces and homogenized with $10 \mathrm{~mL}$ phosphate buffer pH 7.4 by tissue homogenizer. The homogenized sample was subjected to ultrasonication for $10 \mathrm{~min}$ for complete extraction of drug. This solution extract was centrifuged at $5000 \mathrm{rpm}$ for $10 \mathrm{~min}$. The supernatant was collected and analyzed by UV spectroscopy by measuring absorbance at wavelength of $428 \mathrm{~nm}$.

\section{Data and statistical analysis}

The steady-state flux $\left(J, \mu \mathrm{g} / \mathrm{cm}^{2} / \mathrm{h}\right)$ was calculated from the slope of linear plot of the cumulative amount permeated per unit area $\left(\mu \mathrm{g} / \mathrm{cm}^{2}\right)$ as a function of time (h). The lag time $\left(t_{\mathrm{L}}, \mathrm{h}\right)$ was determined from the $x$-intercept of the slope at steady state. The permeability coefficient $\left(\mathrm{KP}, \mathrm{cm}^{2} / \mathrm{s}\right)$ was calculated from the flux and donor drug concentration (Amrutiya et al. 2009).

\section{Result and discussion}

Quasi-emulsion solvent diffusion method has been used for the development of CUR microsponges. These microsponges were filled in capsule shells and were also loaded in carbopol gel. The microsponges were characterized by various parameters and evaluation of the capsules and gel was carried out by different techniques.

\section{Characterization of microsponges}

\section{Particle size analysis}

The production yield (\%) and mean particle size of microsponges are shown in Table 2. It is found that on increasing the drug to polymer ratio, the increase in production yield and mean particle size is observed up to batch MS4, that is having drug to polymer ratio (4:1), but as the drug to polymer ratio is increased $(5: 1)$ the decrease in production yield and entrapment efficiency is observed. This may probably be due to lesser availability of polymer to entrap the drug and the growth in mean particle size may be due to increasing drug to polymer ratio.

\section{Total drug content (TDC) and entrapment efficiency (EE)}

TDC and EE in different formulations were estimated by UV spectrophotometric method. The total drug content and entrapment of the drug depend on the successful molecular association of the drug with the polymers. TDC and EE of the microsponges were found in the range of $24.5 \pm 2.9$ to $97.2 \pm 1.5 \%$ and $21.3 \pm 2.7$ to $93.2 \pm 2.4 \%$ of different batches (Table 2). The values of TDC and EE were found maximum for the formulation MS4 having the drug to polymer ratio of 4:1. A drop in TDC and EE was observed on further increasing drug/polymer ratio. The probable reason for this decrease in TDC and EE could be that the optimum concentration of polymer is not available to coat or entrap the drug molecules.
Table 2 Effect of drug to polymer ratio on various parameters

\begin{tabular}{llllcc}
\hline $\begin{array}{l}\text { Formulation } \\
\text { code }\end{array}$ & $\begin{array}{l}\text { Drug/polymer } \\
\text { ratio }\end{array}$ & $\begin{array}{l}\text { Total drug con- } \\
\text { tent }(\%)\end{array}$ & $\begin{array}{l}\text { Production yield } \\
(\% \pm S D)\end{array}$ & $\begin{array}{l}\text { Mean particle } \\
\text { size }(\mu \mathrm{m})\end{array}$ & $\begin{array}{l}\text { Entrapment } \\
\text { efficiency }(\%)\end{array}$ \\
\hline MS1 & $1: 1$ & $24.5 \pm 2.9$ & $57.3 \pm 1.5$ & $97.4 \pm 2.9$ & $21.3 \pm 2.7$ \\
MS2 & $2: 1$ & $32.2 \pm 3.5$ & $66.6 \pm 2.8$ & $103.5 \pm 1.8$ & $30.2 \pm 2.3$ \\
MS3 & $3: 1$ & $59.8 \pm 3.3$ & $85.3 \pm 2.3$ & $163.4 \pm 2.7$ & $55.8 \pm 2.5$ \\
MS4 & $4: 1$ & $97.2 \pm 1.5$ & $95.2 \pm 1.3$ & $183.6 \pm 2.3$ & $93.2 \pm 2.4$ \\
MS5 & $5: 1$ & $64.7 \pm 2.1$ & $77.2 \pm 3.2$ & $196.9 \pm 3.0$ & $61.7 \pm 2.2$ \\
\hline
\end{tabular}




\section{Fourier transform infrared spectroscopy}

Figure 1 exhibits the FTIR spectra of CUR, EC and CUR microsponge. In spectra of CUR, as shown in Fig. 1a, the characteristic transmittance bands were observed at 1597 , 1505,1275 , and $1157 \mathrm{~cm}^{-1}$ corresponding to stretching $-\mathrm{C}=\mathrm{C}$ vibrations of benzene, aromatic $-\mathrm{C}-\mathrm{O}$ stretching of $(-\mathrm{OMe}$ and $-\mathrm{OH})$, and $-\mathrm{C}-\mathrm{O}-\mathrm{C}$ stretching $(-\mathrm{OMe})$. Further, characteristic bands for phenolic $-\mathrm{OH}$ and conjugated ketonic $-\mathrm{C}=\mathrm{O}$ vibrations were observed at $3500 \mathrm{~cm}^{-1}$. The spectra of EC, Fig. 1b, show the characteristic absorption of alcoholic hydroxyl groups at $3476.71 \mathrm{~cm}^{-1}$; the continuous several absorption peaks in range of $2900-2800 \mathrm{~cm}^{-1}$ and $1300-1000 \mathrm{~cm}^{-1}$ represent the ethoxyl groups while the spectra of CUR microsponges (Fig. 1c) show broadening of band at around $3400 \mathrm{~cm}^{-1}$ and characteristic bands in the range $1597-950 \mathrm{~cm}^{-1}$. However, comparison of the spectra demonstrated no new characteristic peaks in the microsponge which indicated no physical or chemical interactions between curcumin and carrier polymer.

\section{Differential scanning calorimetry}

Figure 2 represents the thermogram of CUR, EC and CUR microsponges. Ethyl cellulose being an amorphous substance does not possess sharp endothermic peaks whereas the thermogram of CUR shows a sharp endotherm at $184.48^{\circ} \mathrm{C}$ with heat of fusion of $137.1 \mathrm{~J} / \mathrm{g}$ corresponding to its melting point. The thermogram of curcumin microsponges shows a broad endotherm at $82.83^{\circ} \mathrm{C}$, a sharp endotherm at $176.57{ }^{\circ} \mathrm{C}$ and an exotherm at $199.933{ }^{\circ} \mathrm{C}$ with heat of fusion of $83.56 \mathrm{~J} / \mathrm{g}, 82.81 \mathrm{~J} / \mathrm{g}$ and $57.93 \mathrm{~J} / \mathrm{g}$, respectively. The shifting of endotherms and appearance of a new exotherm and decrease in heat of fusion indicate that some modifications have occurred.

\section{Scanning electron microscopy}

Figure 3 exhibits the SEM showing surface morphology of CUR microsponges. SEM micrographs displayed that microsponges formed are predominantly spherical and entire curcumin crystals are not seen.
Fig. 1 FTIR spectra of (a) CUR, (b) EC and (c) CUR microsponges

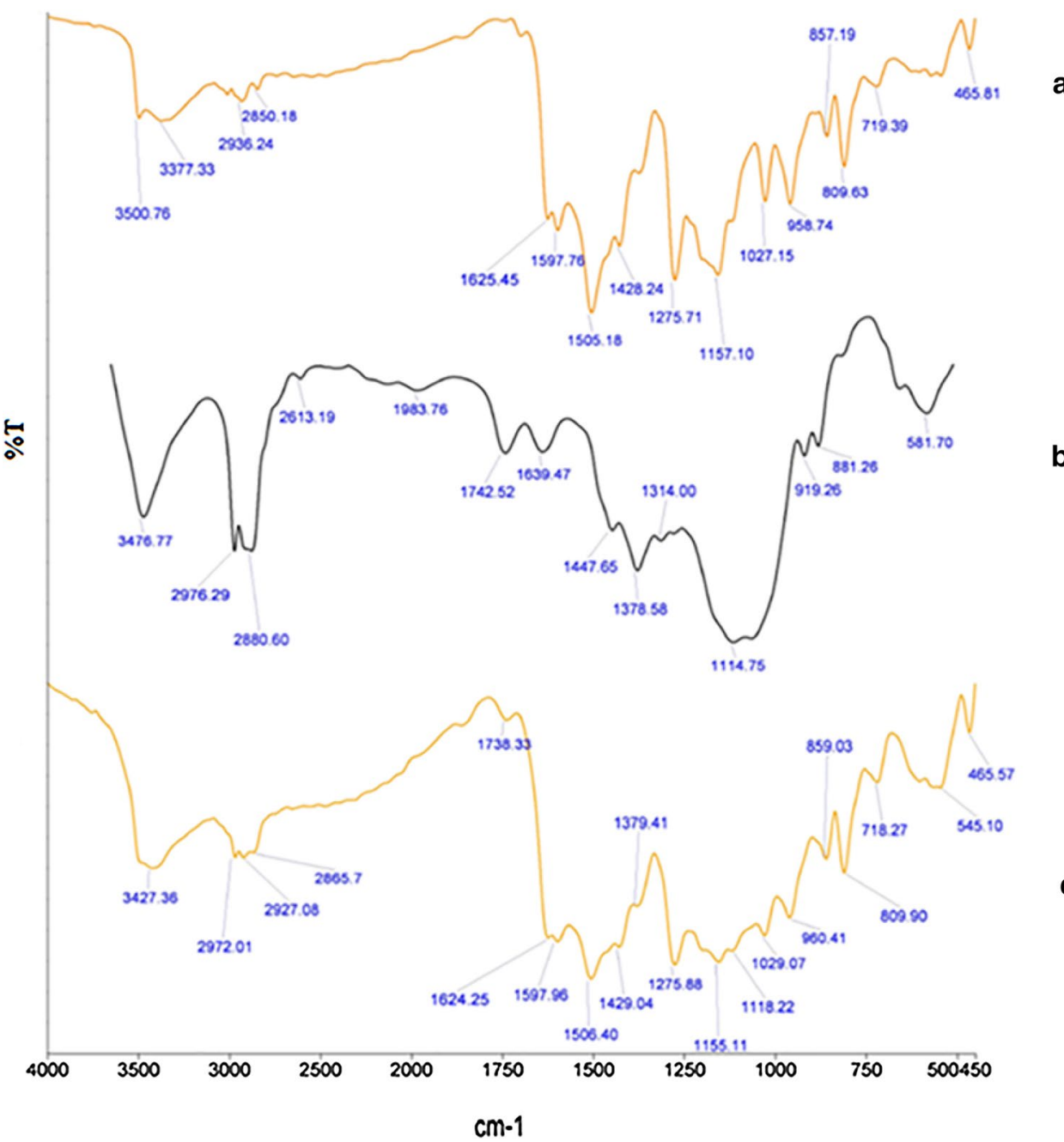

a

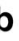


Fig. 2 DSC of curcumin, ethyl cellulose and microsponge

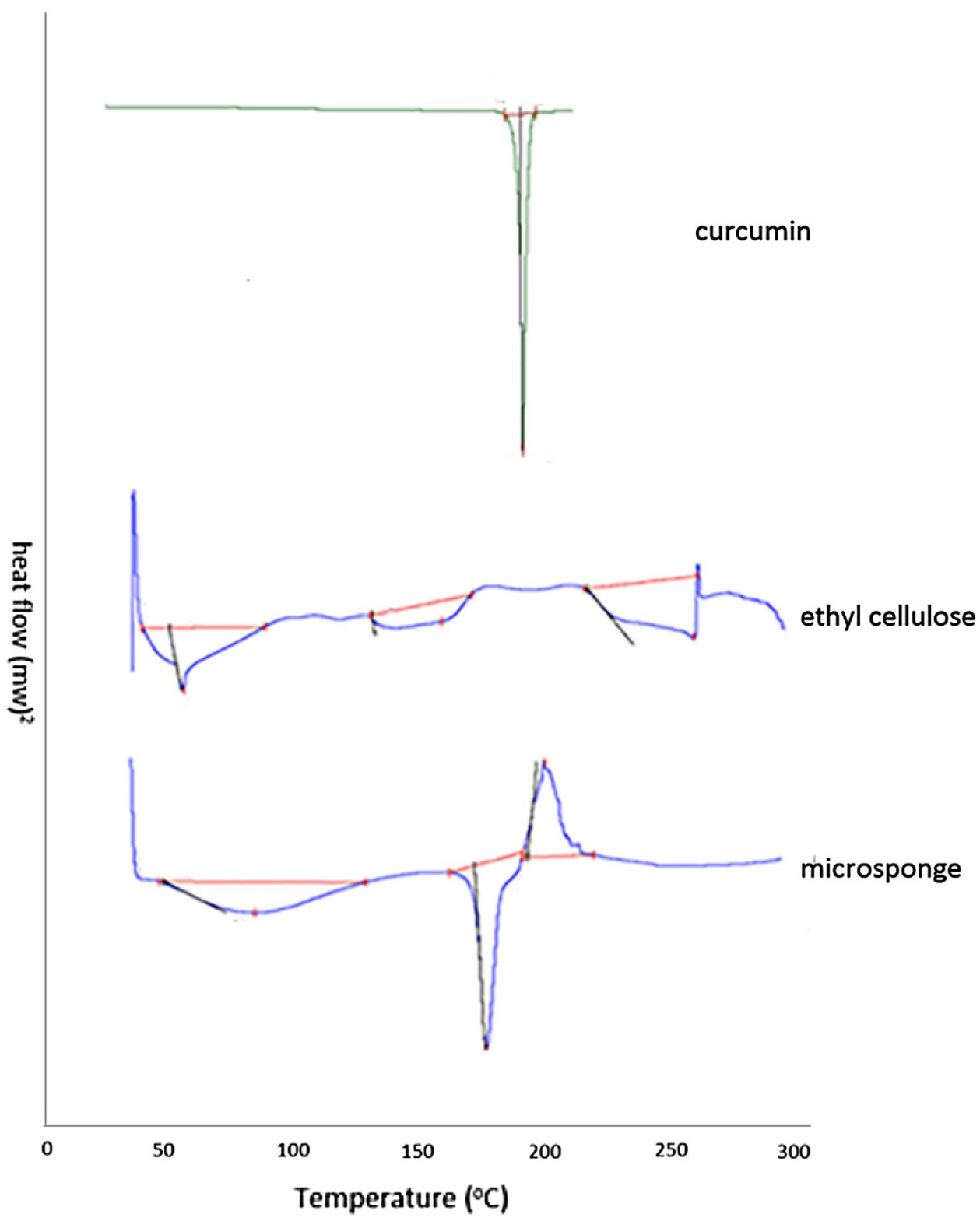

\section{X-ray diffraction study}

Figure 4 displays the X-ray diffraction spectra of CUR, EC and CUR microsponge. X-ray diffractogram of EC is typical of amorphous materials with no sharp peaks. The spectra of CUR show sharp peaks at $17^{\circ}, 22^{\circ}, 24^{\circ}, 30^{\circ}(2 \theta)$ indicating the crystalline nature of curcumin, while the diffractogram of CUR microsponge shows sharp peaks at $18^{\circ}, 24^{\circ}, 38^{\circ}$ $(2 \theta)$ with decreased intensity which indicates decrease in crystalline nature of the microsponge.

\section{Stability study}

The batch MS4 was subjected to 3-month stability study at accelerated conditions and was analyzed for physical

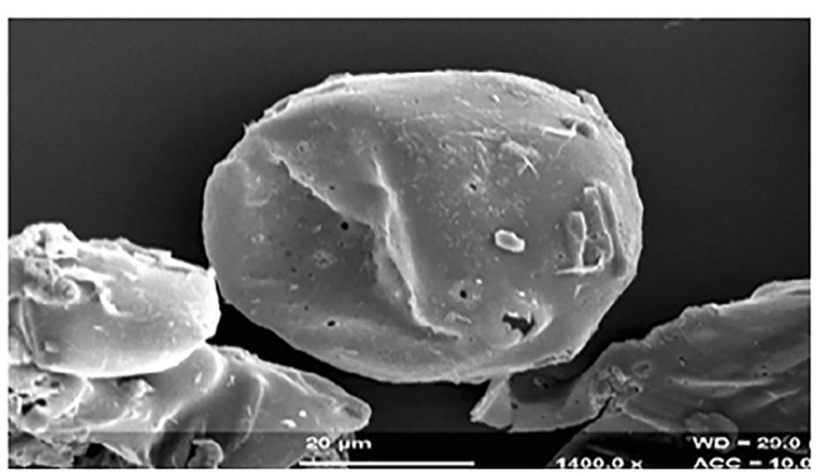

Fig. 3 SEM image of CUR microsponges 


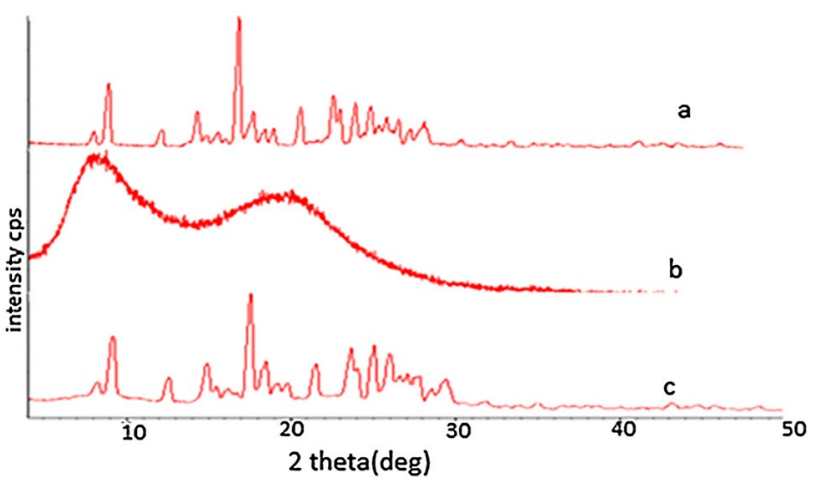

Fig. 4 XRD spectra of (a) CUR, (b) EC and (c) CUR microsponges

appearance, in vitro drug release and FTIR spectroscopy. After 3 months, the formulation was found with no significant change in its appearance. The in vitro percentage drug release came out to be 91.45 similar and also the FTIR spectra revealed no sign of instability. Thus, all these parameters suggested that the formulation MS4 may have good shelf life.

\section{Evaluation of capsules}

The average weight of capsule formulations was found to be within pharmacopoeial limit. The disintegration of the capsule formulations took to be in the range of $17-25 \mathrm{~min}$ that is also within the specified limits as the maximum disintegration time for capsule is $30 \mathrm{~min}$.

\section{In vitro drug release study}

All the batches of CUR microsponges-loaded capsules were evaluated for drug release behavior. Figure 5a displays the in vitro release profile of CUR from various batches using USP type I dissolution apparatus. The drug release was determined in methanolic phosphate buffer ( $\mathrm{pH}$ 7.4) maintained at temperature of $37.0 \pm 0.5^{\circ} \mathrm{C}$ and stirred at $50 \mathrm{rpm}$ for $8 \mathrm{~h}$. It can be inferred from the graph that the batch MS4 shows $93.2 \%$ release for curcumin in microsponges, whereas the equivalent amount of pure CUR shows only $11.7 \%$ of release in $8 \mathrm{~h}$. Therefore, it is inferred from the study that microsponges 2 have displayed enhanced dissolution of curcumin as compared to pure drug. The release rate data of CUR microsponges-loaded capsules were fitted into various kinetics models to estimate their release kinetics and mechanism of release. The release kinetics data were found to be fitted best into the zero-order model $\left(R^{2}=0.996\right)$ for curcumin in microsponges with anomalous transport mechanism of drug release.

\section{Evaluation of microsponge gel}

\section{Visual examination}

The non-opaque pale yellow gel with a pH of $6.42 \pm 0.415$ was formed with no-phase separation that indicated the homogeneity of the preparation.

\section{Spreadability and viscosity}

An apparatus suggested by Mutimer et al. (1956) modified suitably in the laboratory and was used for spreadability study. The result of spreadability is shown in Table 3. Viscosity of carbopol and microsponge gel was determined using Brookfield viscometer. There is no significant difference in viscosity of both the gels and a drop in viscosity is observed with the increasing rpm for both the gels as shown in Fig. 5b.

\section{Mechanical characterization}

The topical formulation must exhibit acceptable mechanical characteristics such as low hardness and high adhesiveness. The maximum detachment force; $F_{\max }$, i.e., hardness and work of adhesion; $\mathrm{W}_{\mathrm{ad}}$ is determined by the plots of force versus distance data for carbopol gel and microsponges gel using texture analyzer. The height of the peak is the maximum force required to separate the probe from the gel (i.e., $\left.F_{\text {max }}\right)$ and the total amount of forces involved in the probe withdrawal from the gel $\left(W_{\mathrm{ad}}\right)$ is calculated from the area under the force versus distance curve. The texturograms as shown in Fig. 6a, b displayed hardness and work of adhesion of carbopol gel and microsponges gel, respectively. It was observed from Fig. 6a that hardness, i.e., $F_{\max }$ is $3.85 \pm 0.36 \mathrm{~g}$ and work of adhesion is found to be $17.43 \mathrm{~g}$.s. for carbopol gel, whereas the Fig. $6 \mathrm{~b}$ shows the hardness and work of adhesion are $3.4 \pm 0.1 \mathrm{~g}$ and $16.08 \mathrm{~g}$.s. of microsponges gel. Hence, no significant difference is observed in the hardness and adhesiveness of the gels.

\section{Ex vivo drug deposition studies}

Figure $5 \mathrm{c}$ shows the ex vivo drug release profile of curcumin indicating that microsponge-loaded gel improved the drug residence time in skin and therapeutic drug concentrations were maintained for a prolonged period with $77.5 \%$ drug release in $24 \mathrm{~h}$. At the end of the study, the drug (CUR) remained in the skin was found to be $207.61 \pm 5.03 \mu \mathrm{g} / \mathrm{cm}^{2}$ as determined by homogenizing the skin with $10 \mathrm{~mL}$ phosphate buffer $\mathrm{pH}$ 7.4. This solution extract was centrifuged and the supernatant was analyzed at a wavelength of $428 \mathrm{~nm}$ using UV-Vis spectroscopy. The permeation flux and permeability coefficient are found to be $10.876 \mu \mathrm{g} \mathrm{cm}^{-2} \mathrm{~h}^{-1}$ 

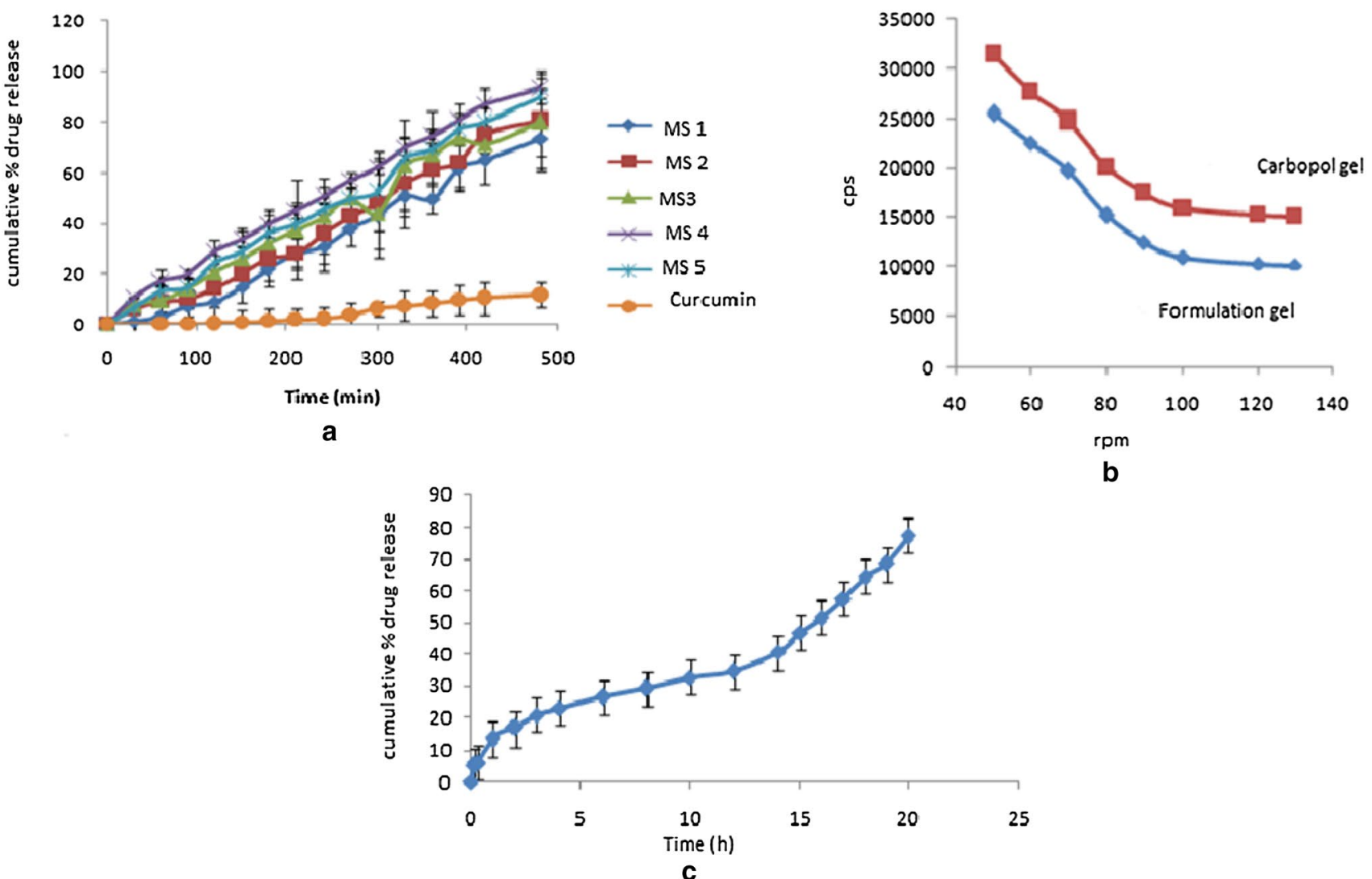

Fig. 5 a In vitro drug release profile of curcumin, b viscosity of carbopol gel and curcumin microsponge gel, $\mathbf{c}$ ex vivo drug release profile of curcumin

Table 3 Evaluation of spreadability, hardness and adhesiveness of gels

\begin{tabular}{llll}
\hline Formulation & $\begin{array}{l}\text { Spreadability } \\
\text { (diameter in } \mathrm{cm})\end{array}$ & Hardness (g) & $\begin{array}{l}\text { Adhe- } \\
\text { siveness } \\
\text { (g.s.) }\end{array}$ \\
\hline Carbopol gel & 2.6 & $3.85 \pm 0.36$ & 17.43 \\
Formulation gel & 1.8 & $3.40 \pm 0.1$ & 16.08 \\
\hline
\end{tabular}

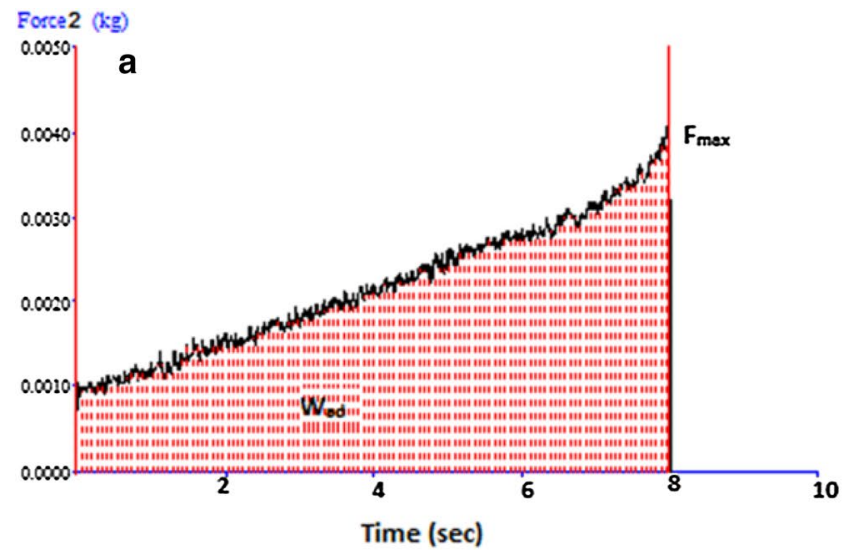

Fig. 6 Texture analysis of a carbopol gel and b CUR microsponges gel and $0.3625 \times 10^{-6} \mathrm{~cm}^{2} \mathrm{~h}^{-1}$, respectively, calculated from the slope of a linear plot of the cumulative amount permeated per unit area $\left(\mu \mathrm{g} / \mathrm{cm}^{2}\right)$ as a function of time (h). This ex vivo drug release profile data were found to be fitted best into the zero-order model $\left(R^{2}=0.921\right)$ with anomalous transport mechanism of drug release.

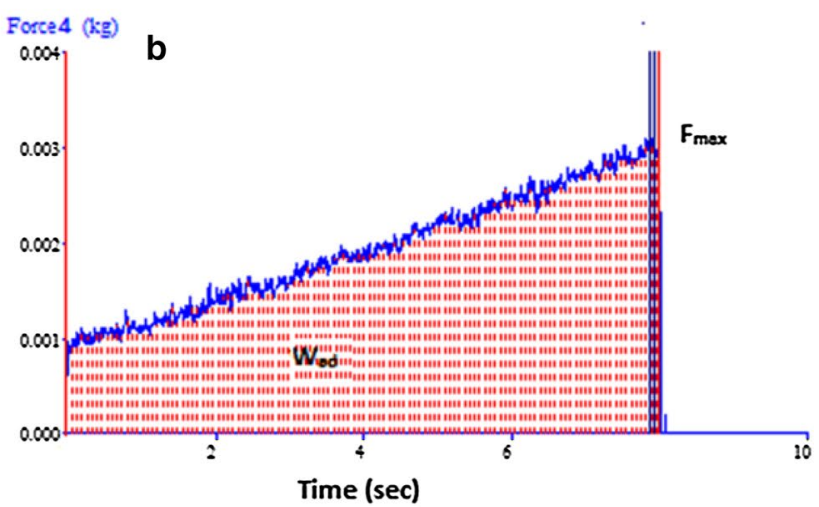




\section{Conclusion}

The objective of developing polymeric microsponge delivery system was to deliver curcumin in a sustained manner for an extended period of time, to reduce frequency of administration and to improve its bioavailability. Therefore, in the present study curcumin microsponges were prepared by simple, reproducible and rapid quasi-emulsion solvent diffusion method. The formulation was characterized by FTIR, DSC, SEM, and XRD studies. The prepared microsponges were then incorporated in capsule dosage form and were loaded in carbopol gel. Varied drug-polymer ratio reflected a remarkable effect on particle size, total drug content and encapsulation efficiency. The batch MS4 possesses the maximum TDC of $97.2 \%$ and entrapment efficiency of $93.2 \%$ with a production yield of $95.2 \%$. The curcumin microsponges filled in the capsule shells showed $93.2 \%$ release of curcumin in $8 \mathrm{~h}$ study following zero-order release kinetics with anomalous transport mechanism of drug release. Further, the curcumin microsponges loaded in the carbopol gel showed $77.5 \%$ of drug release in $24 \mathrm{~h}$ as determined by the ex vivo drug release profile study carried out using a Franz diffusion cell. The amount of drug remained in the skin was found to be $207.61 \pm 5.03 \mu \mathrm{g} / \mathrm{cm}^{2}$. The drug release profile data were found to be fitted best into the zero-order model $\left(R^{2}=0.921\right)$ with anomalous transport mechanism of drug release. Thus, curcumin microsponges prepared in this study were found to be promising as newfangled delivery system offering prolonged release of drug and, hence, would be more useful than conventional formulation therapy in oral as well as in topical drug delivery.

Acknowledgements The authors are grateful to CIL/SAIF, Panjab University, Chandigarh, for instrument facility.

\section{Compliance with ethical standards}

Conflict of interest The authors (M. Bhatia, M. Saini) declare that they have no conflict of interest.

Research involving human participants and animals This article does not contain any studies with human and animal subjects performed by any of the authors.

Open Access This article is distributed under the terms of the Creative Commons Attribution 4.0 International License (http://creativeco mmons.org/licenses/by/4.0/), which permits unrestricted use, distribution, and reproduction in any medium, provided you give appropriate credit to the original author(s) and the source, provide a link to the Creative Commons license, and indicate if changes were made.

\section{References}

Amrutiya N, Bajaj A, Madan M (2009) Development of microsponges for topical delivery of mupirocin. AAPS PharmSciTech 10(2):402-409

Arya P, Pathak K (2014) Assessing the viability of microsponges as gastro retentive drug delivery system of curcumin: optimization and pharmacokinetics. IJP 460(1-2):1-12

Aziz HA, Peh KK, Tan YTF (2007) Solubility of core materials in aqueous polymeric solution effect on microencapsulation of curcumin. Drug Dev Ind Pharm 33(11):1263-1272

Bhatia M, Ahuja M (2013) Thiol modification of psyllium husk mucilage and evaluation of its mucoadhesive application. Sci World J 2013:284182

Bothiraja C, Gholap AD, Shaikh KS (2014) Investigation of ethyl cellulose microsponge gel for topical delivery of eberconazole nitrate for fungal therapy. Ther Deliv 5(7):781-794

Deshmukh K, Poddar SS (2012) Tyrosinase inhibitor-loaded microsponge drug delivery system: new approach for hyperpigmentation disorders. J Microencapsul 29(6):559-568

Echevarria L, Blanco-Prieto MJ, Campanero MA, Santoyo S (2003) Development and validation of a liquid chromatographic method for in vitro mupirocin quantification in both skin layers and percutaneous penetration studies. J Chromatogr 796(2):233-241

Higuchi T (1961) Rate of release of medicaments from ointment bases containing drugs in suspension. J Pharm Sci 50(10):874-875

Jain V, Singh R (2011) Design and characterization of colon-specific drug delivery system containing paracetamol microsponges. ARCH Pharm Res 34(5):733-740

Jain V, Singh R (2010) Dicyclomine-loaded Eudragit@-based microsponge with potential for colonic delivery: preparation and characterization. Trop J Pharm Res. https://doi.org/10.4314/ tjpr.v9i1.52039

Jain V, Jain D, Singh R (2011) Factors affecting the morphology of Eudragit S-100 based microsponges bearing dicyclomine for colonic delivery. J Pharm Sci 100(4):1545-1552

Jangde R (2011) Microsponges for colon targeted drug delivery system: an overview. Asian J Pharm Technol 1:87-93

Kumar PM, Ghosh A (2017) Development and evaluation of silver sulfadiazine loaded microsponge based gel for partial thickness (second degree) burn wounds. EJPS 96:243-254

Li SS, Li GF, Liu L (2013) Evaluation of paeonol skin-target delivery from its microsponge formulation: in vitro skin permeation and in vivo microdialysis. PLoS One 8(11):79-81

Mathew ST, Devi SG, Prasanth VV, Vinod B (2009) Formulation and in vitro-in vivo evaluation of ketoprofen-loaded albumin microspheres for intramuscular administration. J Microencapsul 26(5):456-469

Mine O, Erdal C, Ahmet A (2006) Design and evaluation of colon specific drug delivery system containing flurbiprofen microsponges. IJP 318(1-2):13-117

Mutimer MN, Riffkin C, Hill JA, Glickman ME, Cyr GN (1956) Modern ointment base technology II. Comparative evaluation of bases. J Am Pharm Assoc 45(4):212-218

Ornchuma N, Raymond MS, Wim EH (2014) Curcumin nanoformulations: a review of pharmaceutical properties and preclinical studies and clinical data related to cancer treatment. Biomaterials 35(10):3365-3383

Osmani RA, Aloorkar NH, Ingale DJ (2015) Microsponges based novel drug delivery system for augmented arthritis therapy. Saudi Pharm J 23(5):562-572

Padamwar MN, Pokharkar VB (2006) Development of vitamin loaded topical liposomal formulation using factorial 
design approach: drug deposition and stability. Int $\mathbf{J}$ Pharm 320(1-2):37-44

Pawar AP, Gholap AP, Kuchekar AB, Bothiraja C, Mali AJ (2015) Formulation and evaluation of optimized oxybenzone microsponge gel for topical delivery. J Drug Deliv 2015:261068

Riyaz Ali MO, Nagesh HA, Dipti JI, Parthasarathi KK, Dandasi JD (2015) Microsponges based novel drug delivery system for augmented arthritis therapy. SPJ 23(5):562-572

Salwa S, Ghada EAA, Makhlouf AIA (2018) Improved vaginal retention and enhanced antifungal activity of miconazole microsponges gel, formulation development and in vivo therapeutic efficacy in rats. EJPS 114:255-266
Pharmacopoeia I (2007) The Indian pharmacopoeia commission. Central Indian Pharmacopoeia Laboratory, Ministry of Health and Family Welfare, Govt of India, Sector 23

Publisher's Note Springer Nature remains neutral with regard to jurisdictional claims in published maps and institutional affiliations. 